\title{
Are you (not) expecting? The unforeseen benefits of job training on teenage pregnancy
}

\author{
Rafael Novella ${ }^{1 *}$ (D) and Laura Ripani ${ }^{2}$
}

\author{
*Correspondence: \\ rnovella@iadb.org \\ ${ }^{1}$ Inter-American Development \\ Bank, 1300 New York Avenue, N.W., \\ 20577, Washington, D.C., USA \\ Full list of author information is \\ available at the end of the article
}

\begin{abstract}
Teenage pregnancy in the Dominican Republic represents a persistent development challenge. This paper uses data from a randomized impact evaluation of the youth training program Juventud y Empleo, which includes soft skills training, to examine its impact on teenage pregnancy. We find that the program reduces the probability of teenage pregnancy by 8 percentage points (about $20 \%$ ), particularly among teenagers who are not already mothers. The program seems to affect teenage pregnancy through improvements in soft skills and expectations, among other channels. In addition, we find that the program plays a protective role for teenagers from more deprived backgrounds.
\end{abstract}

JEL Classification: J24, J13, 015

Keywords: Teenage pregnancy, Youth training programs, Soft skills, Dominican Republic

\section{Introduction}

Teenage pregnancy is among the most pervasive problems affecting the social and economic empowerment of young women around the world. The Latin America and the Caribbean (LAC) region has the second highest adolescent fertility rate, after SubSaharan Africa. The Dominican Republic, after Nicaragua, is the most affected country within LAC, ${ }^{1}$ with 100 births per 1000 women ages $15-19 .^{2}$ This paper studies the effects of one of the country's youth training programs, Juventud y Empleo (JE), on teenage pregnancy and shows that improving youths' soft skills and personal expectations reduces the incidence of pregnancy at a young age.

The determinants of teenage pregnancy and motherhood are still widely discussed. The literature about this topic sheds some light on causes by analyzing the impact of teenagers' family backgrounds (Wolfe et al. 2001) and welfare and family planning policies (Acs 1996; An et al. 1993; Kearney and Levine 2012; Lundberg and Plotnick 1990; 1995). ${ }^{3}$ However, there is still a lot to learn about the factors behind the decision to have a child at young age. Parental expectations about school choices seem to be important for teenagers deciding whether to have children soon (Rascon-Ramirez 2014), which may reflect that perceived opportunity costs are an important decision-making factor. At the same time, adolescent attitudes seem to play a role in teen birth rates, as described in a recent study about the impact of MTV's 16 and Pregnant (Kearney and Levine 2014).

(c) The Author(s). 2016 Open Access This article is distributed under the terms of the Creative Commons Attribution 4.0 International License (http://creativecommons.org/licenses/by/4.0/), which permits unrestricted use, distribution, and reproduction in any medium, provided you give appropriate credit to the original author(s) and the source, provide a link to the Creative Commons license, and indicate if changes were made. 
There is also a debate about the impacts of teenage pregnancy and motherhood on labor market outcomes. Despite their differences on magnitude of the impacts, the majority of studies point to a negative impact of teenage pregnancy and motherhood on human capital investments, the probability of getting married, and other consequences, such as performing worse in the labor market (Ashcraft and Lang 2006; Ermisch and Pevalin 2005). ${ }^{4}$ A recent study (Cygan-Rehm and Riphahn 2014) finds that teenage pregnancies rise in times of high (youth) unemployment. This could suggest that opportunity costs matter to young women who think they do not have a chance of finding a good job. Such women cannot gain social recognition from working, so they may decide to get it by having a child at a young age.

Recent evidence for LAC also shows that, in general, there is a negative impact of teenage pregnancy on socioeconomic outcomes. For instance, looking at short-term effects in Mexico, teenage pregnancy seems to reduce teenagers' years of schooling, school attendance, and hours of work while increasing marriage rates (Azevedo et al. 2012). In the long run, being a mother at a young age reduces years of education and per capita household income and contributes to a higher probability of being married or divorced (Arceo-Gomez and Campos-Vazquez 2014). In Chile, Berthelon and Kruger (2014) find that teenage motherhood significantly reduces the probability of the teenager's high school completion. A recent regional study for LAC (Näslund-Hadley and Binstock 2010) argues that the main determinant of teenage pregnancy is not the lack of information about skills for planning for the future but the lack of willingness to use them. And in the Dominican Republic, according to Carrasco (2012), teenage pregnancy is related to a lack of life goals, low incentives to go to school, and a perceived lack of opportunities, especially among the poorest population tier; all these aspects are addressed in this paper. Similarly, a regional report of the World Bank (2012) finds that poverty and lack of opportunities are key determinants of childbearing.

In this sense, interventions targeted at increasing the opportunity cost of being a teenage mother (for instance, through improvements in self-esteem, personal plans for the future, or perceptions about the future) are expected to reduce pregnancy rates. Empirical studies from the USA and the UK show that teenagers' higher attitudes and expectations about their future negatively affect the probability of pregnancy (Plotnick 1992; 1993; 2007). Similarly, evidence from Peru suggests that girls with poor self-efficacy and low educational aspirations are at higher risk of teenage motherhood (Favara et al. 2016). Life skills training programs, such as JE in the Dominican Republic, are examples of interventions aimed at changing expectations and soft skills that might affect teenage pregnancy. ${ }^{5}$

Young men and women in LAC are facing disproportionate difficulties in the labor market: unemployment or bad-quality jobs. ${ }^{6}$ There is also a high percentage of youth who are neither working nor studying, and many are not even looking for a job. Since the early 1990s, some LAC countries have addressed this by implementing job-training programs specially tailored for youth. These programs regularly target vulnerable youth and include training in soft $^{7}$ and technical skills plus apprenticeships or internships in the private sector. ${ }^{8}$ JE was the first such program in LAC to have an experimental evaluation design from its inception. While previous evaluations of these programs have focused almost exclusively on labor market impacts (employment rate, labor earnings, and quality of employment), Ibarrarán et al. (2014) also report on the mechanisms by which training 
is supposed to improve participants' labor market performance, particularly JE's emphasis on the skills-especially soft skills-with which youth join the labor force. The paper also preliminarily examines other important outcomes that can be attributed to training, such as changes in teenage pregnancy rates and consumption of alcohol, cigarettes, drugs, and lottery.

This paper is different mainly in that (i) our definition of teenage pregnancy considers a how many times a woman has been pregnant, not just if a woman is pregnant at the moment of the follow-up survey; (ii) we attempt to estimate the simultaneous effect of JE on soft skills and teenage pregnancy; (iii) we estimate whether JE heterogeneously affects teenage pregnancy by civil status, number of children, and pre-intervention individual (self-esteem) and household characteristics (wealth index); and (iv) we also explore the association of JE and teenage fatherhood.

The vast majority of the previous studies about teenage pregnancy and labor market outcomes are based on associations. These papers find it difficult to solve the potential endogeneity problem of unobserved factors affecting both adolescent pregnancy and labor market outcomes. We use the randomized experimental data of the JE program, which allow us to identify the causal effect of the program on teenage pregnancy. This paper contributes to a better understanding of how youth training programs that include training in soft skills affect teenage pregnancy. At the same time, it enriches the discussion about which elements are important in the agenda of reducing teenage pregnancy in developing countries.

Our analysis is based on a sample of applicants for the cohort of trainees who participated in the 2008 version of the JE program. ${ }^{9}$ We find that the program reduces the probability of pregnancy for all women but has a particularly strong effect for teenagers (reduction of about 8 percentage points in the probability of being pregnant or, in other words, women in the treatment group are $20 \%$ less likely to be pregnant than those in the control group), especially those who are not already mothers. This is mainly achieved through training on soft skills and stressing expectations of students. Moreover, JE has larger effects on teenagers whose initial self-esteem did not fall within the highest or lowest quartile and among teenagers from poorer households. ${ }^{10}$

The rest of the paper is organized as follows: Section 2 describes the JE program, its previous evaluations, and our data. Section 3 presents the empirical strategy, Section 4 presents the results, and Section 5 concludes.

\section{The youth and employment program (Juventud y Empleo)}

Begun in 2001, JE is aimed at increasing the probability that youth aged 16 to 29 years who did not complete high school are able to get a good job. As JE is constantly evolving, we examine a version with different training content, labor intermediation, and evaluation design than the 2001 version of the program. ${ }^{11}$ In particular, the program we evaluate offers a component of $75 \mathrm{~h}$ of soft skills training plus a component of $150 \mathrm{~h}$ of vocational training for a wide variety of jobs (such as providing administrative assistance, working in a bakery, or styling hair). ${ }^{12}$ The soft skills training includes the following: (i) planning skills: development of the participant's personal life project; (ii) basic cognitive skills: management of basic math and communication skills; (iii) social skills: improved management of social risk situations as well as conflict prevention and negotiation skills; (iv) skills for productive work: promotion of decision-making skills, team collaboration, and 
the ability to work with efficiency and quality; and (v) sensitivity to gender equality and respect of the physical environment. It is important to highlight that the JE training did not explicitly include sex education in the curriculum. The vocational training teaches technical knowledge tailored to the needs of employers.

The two training components are provided by private training institutions (Centros Operadores del Sistema (COS)) that are registered and approved by the national training institution (Instituto Nacional de Formación Técnico Profesional). Participants' COS training is followed by a 3-month internship in the private sector; the internship opportunities are selected by the COS with the objective of matching the participant's technical training with a firm's human resources needs-soft-skills training has the same content regardless of the technical training course pursued. Each COS conducts an open call for applicants and then matches them with their preferred career, based on availability of the matching training course.

Previous literature on the program analyzes two types of cohort samples. The first is the impact evaluation by Card et al. (2011) that analyzes the original design of the program, which considers a sample of applicants who applied to receive training in early 2004, with the follow-up survey was in mid-2005 (10 to 14 months after most trainees had finished their training). This evaluation shows JE having little impact on employment rates, but a $10 \%$ increase in both hourly wages and earnings. The evaluation also shows modest impacts on formality (i.e., probability of holding of a job that offers health insurance) for men. ${ }^{13}$ The second impact evaluation of the program (Ibarrarán et al. 2014) used data from 2008 to 2010 and found a positive impact on quality of employment (a $17 \%$ increase on formality for men and a $7 \%$ increase on monthly earnings among employed women and men) but no impact on employment rates.

Ibarrarán et al. (2014) also find unexpected results, foremost among them is a 5percentage-point reduction in teenage pregnancy in the treatment group. These findings are consistent with incremental changes in participants' expectations and soft skills. The 2008 cohort was also surveyed for a second time at the end of 2014 (6 years after treatment), and the results show that the program has additional long-lasting impacts. The most important results show increases of $25 \%$ on formality for men in the treatment group (rather than the $17 \%$ finding in the 2-year follow-up), $31 \%$ on formality for young people living in urban areas, $25 \%$ on formality for older students, and $25 \%$ on earnings for women who live in urban areas (Ibarrarán et al. 2015).

The participants identified as eligible by the COS had to meet the following criteria: (i) be 16 to 29 years of age; (ii) reside in a poor neighborhood; (iii) not be attending school; (iv) have an incomplete high school education or less; (v) be unemployed, underemployed, or occupationally inactive; and (vi) hold a Dominican identity card. ${ }^{14}$ Each randomization process consisted of the COS sending JE information on 35 eligible individuals with interest in JE training. Next, JE verified that the applicants had never previously registered for the program and sent the COS a list of individuals randomly assigned to the treatment or the control group. The treatment group of 20 individuals was formed first, and the control group was formed of the remaining 15 . If individuals were offered the program but either did not respond or dropped out before the tenth day of classes, the COS could replace up to five individuals with people from the control group. In theory, the replacements are randomly selected given that they had initially been one of the 35 randomly selected participants. But in practice, the COS had a 
degree of discretion in selecting the five replacements from the 15 people in the control group.

\section{Empirical strategy}

Our study considers what happened at the random assignment to estimate the intentionto-treat effects of offering the JE program. ${ }^{15}$ The estimates yield the causal effect of offering the program (Duflo et al. 2007), and its estimation includes the group of eligible people who participated in the random assignment.

The data used in this paper corresponds to a baseline collected at registration at the COS for 10,309 eligible applicants (63\% women), from which 5000 individuals (3130 women, including 810 adolescent women) were randomly selected to participate in a survey 18 to 24 months (between November 2010 and February 2011) after courses had completed. ${ }^{16}$ Attrition rates between waves for the whole sample (19\%), the sample of all women (19\%), and the sample of adolescent women $(21 \%)$ are statistically similar between the treatment and control groups. ${ }^{17}$ The final sample corresponds to 2227 women aged 16-29 at the baseline (564 are adolescents, aged 16-19, with complete information in all the variables used in the analysis). ${ }^{18}$

The dependent variable in Eq. (1) corresponds to a dummy variable taking the value of 1 when a woman either is pregnant at the time of the follow-up survey or has a baby after the treatment, and the value of 0 otherwise. One third of the women in our sample are pregnant or were recently pregnant at the time of the follow-up survey. To compute whether a woman has been recently pregnant, we construct the history of births of each female in our sample. In particular, we calculate the number of children born alive between the follow-up and the baseline. ${ }^{19} T_{i}$ corresponds to random assignment to the control or treatment group; $t$ is a dummy variable that takes the value of 0 when the follow-up information was collected in the last 2 months of 2010 and 1 when it was collected in the first 2 months of 2011; $x_{i}$ corresponds to individual characteristics, such as age; and $\epsilon_{i}$ is an individual error term. Because of the random assignment, the correlation between this error term and $T_{i}$ is expected to be 0 , and therefore, the estimation of $\beta$ is unbiased. ${ }^{20}$

$$
\text { pregnancy }_{i}=\alpha+\beta T_{i}+\gamma t_{i}+\delta x_{i}+\epsilon_{i}
$$

In addition, to explore the channels through which JE affects teenage pregnancy, this analysis uses a set of rich information contained in the follow-up survey. In particular, we use information about the youths' expectations and soft skills indexes. ${ }^{21}$ These $j$ variables are the dependent variables estimated separately using Eq. (2).

$$
y_{i}^{j}=\alpha+\beta T_{i}+\gamma t_{i}+\delta x_{i}+\epsilon_{i}
$$

From the expectations module, we compute an index (using principal component factoring analysis) combining the responses to a set of questions regarding expectations about the youths' personal lives. ${ }^{22}$ For measures of soft skills, we use the Social and Personal Competencies Scale (CPS, for its name in Spanish), the Rosenberg self-esteem scale, and the Grit scale, which were standardized within the samples of men and women in the follow-up survey and transformed so higher values indicate higher levels of the dimension measured. Brea (2010) presents a detailed discussion of the construction, reliability, and interpretation of the three scales for the sample of JE. The CPS was designed exclusively to measure the impact of the soft skills modules in JE, and its scale measures 
different dimensions of social and personal competencies related to attitudes and values, including leadership, communication and social acceptance, ability to establish social relationships, empathy and communication, self-esteem, order, organization, and conflict resolution skills. The Rosenberg scale measures self-esteem through questions about participants' feelings, ${ }^{23}$ and the Grit scale (Duckworth et al. 2007) measures perseverance or passion for long-term goals and consistency of interest.

To deal with the simultaneous effect that JE might have on pregnancy, expectations, and soft skills, we also estimate a seemingly unrelated regressions (SUR) model using system of Eq. (3). For the five equations of a given individual, the model is as follows:

$$
\left(\begin{array}{c}
\text { pregnancy } \\
\text { cps } \\
\text { rosenberg } \\
\text { grit } \\
\text { expectations }
\end{array}\right)=\left(\begin{array}{ccccc}
X_{1} & 0 & \ldots & \ldots & 0 \\
0 & X_{2} & \ldots & \ldots & 0 \\
\ldots & \ldots & X_{3} & \ldots & \ldots \\
\ldots & \ldots & \ldots & X_{4} & 0 \\
0 & \ldots & \ldots & 0 & X_{5}
\end{array}\right)\left(\begin{array}{c}
\beta_{1} \\
\beta_{2} \\
\beta_{3} \\
\beta_{4} \\
\beta_{5}
\end{array}\right)+\left(\begin{array}{c}
\epsilon_{1} \\
\epsilon_{2} \\
\epsilon_{3} \\
\epsilon_{4} \\
\epsilon_{5}
\end{array}\right)
$$

Although this model assumes that the error terms have zero mean and are independent across individuals, it takes into account the potential correlation between the error terms across equations for a given individual. To allow the error to be heteroscedastic, we report bootstrapped standard errors.

Finally, using the following specification, we explore whether JE affects teenage pregnancy heterogeneously by the level of some characteristics at the baseline. In particular, we include a dummy for whether a woman was married or cohabitating, her number of children, her self-esteem according to the Rosenberg scale, and a wealth indicator of her household. These variables, included in $h_{i}$, are separately included in the estimation of Eq. (4).

$$
\text { pregnancy }_{i}=\alpha+\gamma t_{i}+\delta x_{i}+\beta\left(T_{i} * h_{i}\right)+\epsilon_{i}
$$

\section{Results}

The linear probability model estimates of the effects of JE on pregnancy (Eq. 1) are shown in Table $1 .{ }^{24}$ Similar to the findings of Ibarrarán et al. (2014), we find that the program reduces the likelihood of pregnancy by about 3 percentage points for all women, which is not statistically significant and is likely due to differences in how pregnancy is defined. However, as models (2) and (3) show, we find a significant effect of JE in the youngest group of women, aged 16-19 years at the baseline. The program reduces their probability of pregnancy by 8 percentage points ( $20 \%$ ), but it has no effect on women aged $20-29$ years.

Table 1 Overall JE effects on pregnancy

\begin{tabular}{llll}
\hline Pregnancy & $(1)$ & $(2)$ & $(3)$ \\
& All women & Age 16-19 & Age 20-29 \\
\hline Treatment & -0.027 & $-0.078^{\mathrm{a}}$ & -0.009 \\
& $(0.020)$ & $(0.041)$ & $(0.024)$ \\
Mean dep. var. for control group & 0.350 & 0.389 & 0.337 \\
Observations & 2227 & 564 & 1663 \\
\hline
\end{tabular}

Notes: Robust standard errors clustered at the course level in parentheses. All models include a dummy variable for whether the follow-up interview was in 2011 and a variable for individual's age

${ }^{a}$ Significant at $10 \%$ 
The next three tables focus on the sample of adolescent women. Table 2 shows the effect of JE on the potential channels through which the program might affect teenage pregnancy: soft skills and expectations. The table corresponds to the estimation of Eq. (2), for the different dependent variables $y_{i}^{j}$ (CPS score, the Rosenberg self-esteem scale, the Grit scale, and the expectations index). In terms of soft skills, JE substantially increases the CPS and Grit scores. Similarly, it increases teenagers' expectations about their future. On the other hand, we find that JE does not affect the Rosenberg self-esteem scale for adolescent women.

The estimates shown in Tables 1 and 2 suggest that the increase in soft skills and expectations about the future might serve as channels through which the JE reduces teenage pregnancy. ${ }^{25}$ To account for the potential correlation of the error terms of the equations of teenage pregnancy, soft skills measures, and expectations for a given teenager, we estimate a SUR model. Table 3 shows the estimates of the impact of JE on the system of Eq. (3).

The Breusch-Pagan test at the bottom of Table 3 confirms that the error terms of these equations are not independent. In addition, Table 3 shows that even considering the impact of JE on the soft skills measures and the expectation index, JE reduces teenage pregnancy, which suggests that JE also affects pregnancy through other channels. ${ }^{26}$

Table 4 explores whether the effect of JE on teenage pregnancy is heterogeneous across different levels of some individual and household characteristics collected at the baseline. The estimates correspond to Eq. (4) where $h_{i}$ refers to a dummy variable for whether the woman is married or cohabiting (model 1), how many children she has (model 2), Rosenberg's self-esteem scale (model 3), and a household wealth indicator (model 4). In models (3) and (4), we centered the variables to different points of their distribution because the value zero falls below the minimum value of these variables.

As expected, being married or cohabiting increases the probability of pregnancy among teenagers. ${ }^{27}$ Even though the JE does not affect married/cohabiting and "single" women differently (coefficient on the interaction term in model 1), Table 4 shows that JE reduces, although not statistically significant, the probability of teenage pregnancy for "single" women (in about 8 percentage points). On the other hand, model 2 shows that JE reduces, by about 11 percentage points (coefficient on treatment), the probability of pregnancy for teenagers who are not already mothers. This is an important result because of the importance of being a mother for the first time and the implications this has on women's careers. The fact that the program has an impact on those who did not have children yet is likely to change the career path for female teenagers.

Table 2 JE effects on soft skills and expectations

\begin{tabular}{lllll}
\hline & $(1)$ & $(2)$ & $(3)$ & $(4)$ \\
& $\begin{array}{l}\text { Total CPS } \\
\text { score }\end{array}$ & $\begin{array}{l}\text { Rosenberg } \\
\text { scale }\end{array}$ & $\begin{array}{l}\text { Total Grit } \\
\text { scale }\end{array}$ & $\begin{array}{l}\text { Expectations } \\
\text { index }\end{array}$ \\
\hline Treatment & $0.172^{\mathrm{a}}$ & -0.010 & $0.212^{\mathrm{a}}$ & $0.305^{\mathrm{b}}$ \\
& $(0.079)$ & $(0.073)$ & $(0.092)$ & $(0.089)$ \\
Mean dep. var. for & -0.024 & 0.128 & -0.124 & -0.175 \\
control group & 564 & 564 & 564 & 564 \\
Observations & 564 & 564
\end{tabular}

Note: Robust standard errors clustered at the course level in parentheses. All models include a dummy variable for whether the follow-up interview was in 2011 and a variable for individual's age

a Significant at $5 \%$, ${ }^{b}$ significant at $1 \%$ 
Table 3 SUR estimation of the JE effects

\begin{tabular}{llllll}
\hline & $(1)$ & $(2)$ & $(3)$ & $(4)$ & $(5)$ \\
& Pregnancy & $\begin{array}{l}\text { Total } \\
\text { CPS } \\
\text { score }\end{array}$ & $\begin{array}{l}\text { Rosenberg } \\
\text { scale }\end{array}$ & $\begin{array}{l}\text { Total } \\
\text { Grit } \\
\text { scale }\end{array}$ & $\begin{array}{l}\text { Expectations } \\
\text { index }\end{array}$ \\
\hline Treatment & $-0.078^{\mathrm{a}}$ & $0.172^{\mathrm{b}}$ & -0.010 & $0.212^{\mathrm{b}}$ & $0.305^{\mathrm{c}}$ \\
& $(0.043)$ & $(0.082)$ & $(0.075)$ & $(0.087)$ & $(0.085)$ \\
Observations & 564 & 564 & 564 & 564 & 564 \\
$R$-squared & 0.011 & 0.008 & 0.005 & 0.013 & 0.044 \\
\multicolumn{2}{l}{ Breusch-Pagan test of independence: } & chi $^{2}(10)=381.240, \operatorname{Pr}=0.0000$ & & \\
\hline
\end{tabular}

Note: Bootstrapped standard errors in parentheses (1000 replications). All models include a dummy variable for whether the follow-up interview was in 2011 and a variable for the individual's age

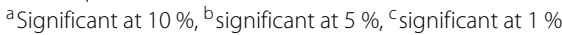

Finally, Table 4 explores how the JE program affects pregnancy at different points in the distribution of self-esteem and a household wealth index. Table 4 shows that the difference in the effect of pre-intervention self-esteem on pregnancy between treatment and control groups is not statistically significant at traditional levels. However, the protective role of self-esteem for the treatment group, relative to the control group,

Table 4 Heterogeneous effects of JE on pregnancy

\begin{tabular}{|c|c|c|c|c|}
\hline \multirow[b]{3}{*}{ Dependent variable: } & \multicolumn{4}{|c|}{ Independent variables $\left(h_{i}\right)$} \\
\hline & $(1)$ & $(2)$ & (3) & (4) \\
\hline & $\begin{array}{l}\text { Married/ } \\
\text { cohabiting }\end{array}$ & $\begin{array}{l}\text { \# of } \\
\text { children }\end{array}$ & $\begin{array}{l}\text { Rosenberg } \\
\text { scale }\end{array}$ & $\begin{array}{l}\text { Life- } \\
\text { Quality }\end{array}$ \\
\hline \multicolumn{5}{|l|}{ Pregnancy } \\
\hline \multirow[t]{2}{*}{ Treatment when $h_{i}=0$} & -0.077 & $-0.105^{a}$ & - & - \\
\hline & $(0.047)$ & $(0.048)$ & - & - \\
\hline \multirow[t]{2}{*}{ Treatment at percentile 5 of $h_{i}$} & - & - & -0.119 & $-0.250^{b}$ \\
\hline & - & - & $(0.089)$ & $(0.079)$ \\
\hline \multirow[t]{2}{*}{ Treatment at percentile 10 of $h_{i}$} & - & - & -0.108 & $-0.211^{b}$ \\
\hline & - & - & $(0.071)$ & $(0.066)$ \\
\hline \multirow[t]{2}{*}{ Treatment at percentile 25 of $h_{i}$} & - & - & $-0.088^{\mathrm{a}}$ & $-0.133^{b}$ \\
\hline & - & - & $(0.047)$ & $(0.046)$ \\
\hline \multirow[t]{2}{*}{ Treatment at percentile 50 of $h_{i}$} & - & - & $-0.073^{\mathrm{a}}$ & -0.066 \\
\hline & - & - & $(0.041)$ & $(0.042)$ \\
\hline \multirow[t]{2}{*}{ Treatment at percentile 75 of $h_{i}$} & - & - & -0.056 & -0.006 \\
\hline & - & - & $(0.054)$ & $(0.051)$ \\
\hline \multirow[t]{2}{*}{ Treatment at percentile 90 of $h_{i}$} & - & - & -0.056 & 0.064 \\
\hline & - & - & $(0.054)$ & $(0.070)$ \\
\hline \multirow[t]{2}{*}{ Treatment at percentile 95 of $h_{i}$} & - & - & -0.050 & 0.111 \\
\hline & - & - & $(0.061)$ & $(0.086)$ \\
\hline \multirow[t]{2}{*}{$h_{i}$} & 0.128 & 0.017 & -0.011 & $-0.013^{b}$ \\
\hline & $(0.080)$ & $(0.056)$ & $(0.008)$ & $(0.005)$ \\
\hline \multirow[t]{2}{*}{ Treatment* $h_{i}$} & 0.050 & 0.092 & 0.006 & $0.014^{a}$ \\
\hline & $(0.108)$ & $(0.075)$ & $(0.010)$ & $(0.006)$ \\
\hline Observations & 564 & 564 & 564 & 564 \\
\hline
\end{tabular}

Note: $h_{i}$ corresponds to baseline characteristics: a dummy variable for whether women were married or cohabiting (model 1); the number of children (model 2); the Rosenberg's self-esteem scale (model 3); and the Life-Quality Index (model 4). All models include a dummy variable for whether the follow-up interview was in 2011 and a variable for individual's age. Robust standard errors clustered at the course level in parentheses

a Significant at $5 \%$, ${ }^{\text {b }}$ ignificant at $1 \%$ 
seems to activate when the Rosenberg's score is not too high or too low (i.e., differences between controls and treatments are statistically significant at percentiles 25 and 50). Teenagers with moderate levels of pre-intervention self-esteem taking the JE training are about 8 to 9 percentage points less likely to be pregnant than those in the control group. On the other hand, JE even further reduces the probability of pregnancy for those teenagers coming from poorer households. The correlation between poverty and pregnancy is also observed in the coefficient on "Life-Quality Index."

In summary, we find that the JE effects are larger among teenage women (16-19 years old), especially those who are single and not already mothers. Moreover, JE plays a protective role for teenagers with pre-intervention moderate levels of self-esteem and for those coming from poorer households.

\section{Conclusions}

This paper examines the impact of the Dominican Republic's JE training program on teenage pregnancy. In contrast with previous evaluations, we include a broader definition of teenage pregnancy, which exploits a woman's whole history of pregnancies; estimate the simultaneous effect of JE on soft skills and teenage pregnancy; estimate whether JE heterogeneously affects teenage pregnancy; and also explore the association of JE and teenage fatherhood.

Our results show that the JE program reduces the probability of pregnancy by about 3 percentage points for all women, but this impact is not statistically significant. However, the impacts are much larger and are statistically significant for women aged 16-19 (8 percentage points or $20 \%$ ). We also find that the program improves the soft skills of young women (measured through different scores) and their expectations about the future. Finally, we find that the effect of JE through these channels is not homogeneous. In particular, we find that JE has a statistically significant impact for single women who are not yet mothers, and it has a protective role for those teenagers with moderate preintervention levels of self-esteem (measured on the Rosenberg scale) and those coming from poorer households.

Even though our analysis shows important effects of JE on teenage pregnancy, it has some limitations that are important to discuss. First, we are not able to disentangle which of the components of the program, or what combination of them, is affecting teenage pregnancy. A second concern is the reduced sample size of adolescent women. Also, even though is not the main focus of the paper, the results about teenage fatherhood should be read with caution because of potential sample selection issues.

In terms of the policy implications of this paper, the main message is that adolescent women with stronger self-esteem and better soft skills and who are more hopeful about the future seem to postpone having children. Youth training programs that include soft skills training can change not only the skills that are necessary to perform better in the labor market, but they also increase self-confidence and expectations about the future. Therefore, youth training programs that usually have a main expected result of improving labor market outcomes might also have unexpected impacts. In this sense, the programs can effectively increase the opportunity cost of having a child at an early stage in life and make young women decide not to have a child at a young age. In contexts of high pregnancy rates, focusing on providing soft skills and vocational training for young girls can 
have positive outcomes on teenage pregnancy rates and therefore on labor market outcomes.

In this sense, the findings of this paper reinforce the idea that there is a need for public interventions in the challenge of decreasing teenage pregnancy rates. It is necessary to implement a comprehensive set of public policies that go beyond just giving information about methods to plan for the future. The policies should also have an impact on improving expectations and augmenting self-esteem and other soft skills, especially for the poorest people within the population. ${ }^{28}$ Eventually, such policies would lead to better opportunities for women in the labor market, improved access to better quality jobs, and better earnings.

\section{Endnotes}

${ }^{1}$ Abortions and miscarriages, among other factors, make adolescent fertility rate lower than the teenage pregnancy rate. However, to the best of our knowledge, there are no comparable statistics of the prevalence of teenage pregnancy across countries and, thus, adolescent fertility rate is widely used as proxy.

${ }^{2}$ According to the World Bank (2014), in 2012, the adolescent fertility rate (i.e., births per 1000 women ages 15-19) was 69 in LAC, 108 in Sub-Saharan Africa, 100 in the Dominican Republic, and 101 in Nicaragua.

${ }^{3}$ In terms of family background and attitudes, the literature shows that teenagers with more educated mothers are less likely to be pregnant at a young age, and there is also an impact of household characteristics such as family structure, family stress factors, parental attitude, expectations, monitoring and control of children, and contraceptive practices. In terms of welfare and family planning policies, the literature shows that the existence of generous welfare programs (such as Medicaid) have increased teenage pregnancy rates and generated intergenerational welfare dependency, and on the other side, higher investments in public family planning policies had the opposite effect, decreasing adolescent pregnancy rates.

${ }^{4}$ According to a classification made by Rascon-Ramirez (2014), the most relevant empirical evidence about the consequences of teenage motherhood may be grouped by consequences on human capital investment and labor market outcomes (Ashcraft and Lang 2006; Chevalier and Viitanen 2003; Fletcher and Wolfe 2009; Hotz et al. 1997; Klepinger et al. 1999; Levine and Painter 2003; Rosenzweig and Wolpin 1995) and partnerships (Ermisch and Pevalin 2005; Goodman GK and Walker 2004; Plotnick 1992).

${ }^{5}$ In the literature, soft skills are also called socio-emotional, non-cognitive, or life skills. They are skills related to attitudes and behaviors and differ from cognitive skills, which are related to the ability to learn and the intellectual coefficient.

${ }^{6}$ As many as 73 million young people aged 15 to 24 are unemployed, and a large proportion of those employed have poor quality jobs; increasing numbers are working part-time and in temporary and informal forms of employment (International Labour Organization 2015).

${ }^{7}$ The academic literature agrees that there is a positive relationship between possessing soft skills and the probabilities of finding a good job and maintaining it for a longer time (Heckman et al. 2006). Focusing on soft skills has become increasingly important for training programs in LAC (Gonzalez Velosa et al. 2012; Ibarrarán and Rosas 2009), where different programs have included or expanded the provision of soft skills. 
${ }^{8}$ See Gonzalez-Velosa et al. (2012) for an in-depth analysis of six job-training programs for youth in LAC, using as inputs the results from impact evaluations, qualitative fieldwork, and a statistical analysis of surveys of firms and program beneficiaries. Other important references are Heckman et al. (1999) for a general overview of training programs and Betcherman et al. (2004) for a summary that includes some evaluations of developing countries' training programs.

${ }^{9}$ The first evaluation of the first version of JE corresponds to Card et al. (2011).

${ }^{10}$ Calero and Rozo (2016) also find evidence of a training program in Brazil affecting teenagers' risk behaviors differently according to their level of socio-emotional skills.

${ }^{11}$ Changes mainly consist in structuring and standardizing the modules of soft skills training and putting more emphasis in the relationship between the classroom training and the private sector internships. For instance, in a qualitative analysis of JE, Fazio (2011) finds additional evidence that private firms value more the $75 \mathrm{~h}$ of soft skills training than the $150 \mathrm{~h}$ of technical training. More specifically, the changes were as follows: (i) training institutions (Centros Operadores del Sistema (COS)) worked closer to the private sector companies in order to have an internship experience much more tailored to the needs of the firm; (ii) the life skills training was modified, better structured, and homogeneously provided by the COS, given that the firms expressed that these skills were highly valued, even more than JE's technical training. Moreover, changes in the evaluation design included the following: (i) the sample for the random assignment was larger for each course (20 individuals in the treatment and 15 individuals in the control groups), and (ii) in general, several aspects of the evaluation were improved, such as the sample size (1349 individuals in the first evaluation and 3761 in the new evaluation design), the survey instruments, and the organization of the fieldwork (supervisors of the interviewers and quality controls in the field at the time of the interviews).

${ }^{12}$ Training took place over an 8-month period, from February to October 2008.

${ }^{13}$ During the first evaluation of the program, people who were originally assigned to receive training but failed to show up or those who attended only briefly were not included in the follow-up survey. This potentially compromised the randomized design of the Card et al.s (2011) JE evaluation.

${ }^{14}$ The eligibility requirement of living in a poor household was related to applicants' location across the country and targeting priorities established by the national government. Data from the program shows that $72 \%$ of the applicants met the location criteria, but only $40 \%$ were poor.

${ }^{15}$ Tables 5 and 6, in Appendix 1, show the balance for the samples of all women and only adolescent women.

${ }^{16}$ The baseline questionnaire collected data on household composition and socioeconomic characteristics, labor force participation, labor history, assets, dwelling materials, and self-esteem. In addition to these modules, the follow-up questionnaire collected data on time use, training courses and internship, consumption, health status, risk aversion, future expectations, pregnancy history, and basic skills, including non-cognitive skills and self-esteem.

${ }^{17}$ Even though attrition is associated to having lower education, being less poor, and living in urban areas, attrition rates between individuals in the treatment and control groups seem to be random, as column (5) in Tables 5 and 6 in Appendix 1 shows. 
${ }^{18}$ Similarly, column (8) in Tables 5 and 6 in Appendix 1 shows that having completed information in the variables used in the analysis is (weakly) different between the treatment and control groups in just a few observable characteristics.

${ }^{19}$ If the age of a child, plus the 9 months of gestation, is smaller than the time lapse between the two waves, the child is considered a newborn and her mother is a recent pregnant woman. Given data restrictions, we are not able to include history of pregnancies or number of miscarriages and abortions of women in the sample. We observe changes only between the baseline and follow-up in the number of live births. Taking this into consideration, we find that JE does not affect motherhood (probability of being mother nor the number of newborns). These results are available on request. In addition, even though we are also able to reconstruct the history of births for males in the sample, severe selection problems make us very cautious about interpreting the results that JE affects neither the probability of being father nor the number of newborns (Tables 9 and 10 in Appendix 1).

${ }^{20}$ Ideally, we would control for course fixed effects. However, reducing the sample to teenagers results in $30 \%$ of the courses with only one observation. To marginally account for common unobservables at the course level, the standard errors allow for heteroscedasticity at course level.

${ }^{21}$ Another possible channel is an incapacitation effect of the JE, through which adolescent women are less likely to engage in risky behaviors when they are in training. However, data limitations do not allow us to analyze this potential channel of JE effects.

${ }^{22}$ Appendix 2 describes the construction of the expectation index in detail.

${ }^{23}$ The JE evaluation questionnaire collected the ten items of the RSE scale. Specifically, individuals were asked to report how much they agree (on a 4-point scale: 1 -strongly agree; 2-agree; 3-disagree; and 4-strongly disagree) with each of the following statements: (1) on the whole, I am satisfied with myself; (2) at times, I think I am no good at all; (3) I feel that I have a number of good qualities; (4) I am able to do things as well as most other people; (5) I feel I do not have much to be proud of; (6) I certainly feel useless at times; (7) I feel that I am a person of worth, at least on an equal plane with others; (8) I wish I could have more respect for myself; (9) all in all, I am inclined to feel that I am a failure; and (10) I take a positive attitude toward myself.

${ }^{24}$ Table 7 in Appendix 1 shows that the marginal effects of the Probit model are similar to the ones of the linear probability model.

${ }^{25}$ While the effect of JE on the CPS scores of female and male teenagers is positive and similar in magnitude, the program affects males' self-esteem and does not affect their Grit or expectations index. Results are available upon request.

${ }^{26}$ Table 8 in Appendix 1 shows the correlation matrix of the residuals of the equations included in Table 3.

27 The linear combination of the coefficient on "Women married or cohabiting" and "Women married or cohabiting*Treatment" is 0.178 , significant at the $99 \%$ level.

${ }^{28}$ In the Dominican Republic, the Inter-Agency Technical Committee for the Prevention of Teen Pregnancy presented the "Strategic Plan to Prevent Teen Pregnancy: Toward a National Policy." This plan is being implemented but has not yet been evaluated. 


\section{Appendix 1}

Table 5 Balance of the sample of women

\begin{tabular}{|c|c|c|c|c|c|c|c|c|c|c|c|}
\hline & \multicolumn{3}{|c|}{ Original randomization } & \multicolumn{4}{|c|}{ Attrited } & \multicolumn{4}{|c|}{ Complete information } \\
\hline & (1) & (2) & $t$ & (3) & (4) & $t$ & (5) & (6) & (7) & $t$ & (8) \\
\hline & Control & Treatment & & Yes & No & & DD & No & Yes & & DD \\
\hline Age & 22.24 & 22.40 & -1.21 & 22.19 & 22.38 & -1.22 & 0.19 & 22.48 & 22.36 & 0.55 & -0.47 \\
\hline Rosenberg's self-esteem score & 23.72 & 23.91 & -1.28 & 23.95 & 23.82 & 0.75 & 0.16 & 23.70 & 23.83 & -0.37 & 0.30 \\
\hline Married & 0.34 & 0.33 & 0.14 & 0.33 & 0.34 & -0.26 & 0.06 & 0.33 & 0.34 & -0.09 & -0.01 \\
\hline Number of children & 0.99 & 1.00 & -0.28 & 0.94 & 1.01 & -1.39 & -0.03 & 1.01 & 1.01 & 0.00 & $-0.25^{a}$ \\
\hline Mother & 0.57 & 0.57 & 0.10 & 0.53 & 0.58 & $-2.49^{c}$ & 0.02 & 0.57 & 0.58 & -0.44 & -0.03 \\
\hline Attends school & 0.23 & 0.23 & 0.04 & 0.20 & 0.24 & $-2.01^{b}$ & -0.03 & 0.27 & 0.24 & 1.46 & -0.03 \\
\hline Incomplete primary educ. & 0.20 & 0.20 & -0.17 & 0.23 & 0.20 & $1.68^{\mathrm{a}}$ & 0.01 & 0.18 & 0.20 & -0.60 & 0.03 \\
\hline Complete primary educ. & 0.06 & 0.05 & 0.70 & 0.05 & 0.05 & -0.22 & 0.00 & 0.07 & 0.05 & $1.71^{\mathrm{a}}$ & -0.01 \\
\hline Incomplete secondary educ. & 0.55 & 0.56 & -0.60 & 0.51 & 0.56 & $-2.43^{b}$ & -0.02 & 0.55 & 0.57 & -0.58 & -0.01 \\
\hline Complete secondary educ. & 0.03 & 0.04 & -0.40 & 0.04 & 0.03 & 0.81 & -0.01 & 0.02 & 0.04 & $-1.85^{\mathrm{a}}$ & 0.03 \\
\hline More than secondary educ. & 0.00 & 0.00 & -1.30 & 0.00 & 0.00 & -0.22 & 0.01 & 0.01 & 0.00 & $1.76^{\mathrm{a}}$ & $-0.01^{\mathrm{a}}$ \\
\hline Missing education & 0.04 & 0.04 & 0.28 & 0.06 & 0.04 & $2.58^{b}$ & 0.01 & 0.06 & 0.03 & $2.56^{\mathrm{b}}$ & -0.01 \\
\hline No data on education & 0.12 & 0.11 & 0.95 & 0.11 & 0.11 & -0.25 & 0.00 & 0.11 & 0.11 & -0.37 & -0.01 \\
\hline Number of jobs & 0.19 & 0.19 & -0.20 & 0.21 & 0.19 & 1.16 & 0.06 & 0.17 & 0.19 & -0.91 & -0.08 \\
\hline Employed & 0.03 & 0.03 & 0.49 & 0.03 & 0.03 & 1.00 & 0.00 & 0.01 & 0.03 & -1.22 & -0.03 \\
\hline Salaried worker & 0.02 & 0.01 & 1.52 & 0.01 & 0.01 & -0.52 & 0.02 & 0.01 & 0.01 & -0.75 & -0.02 \\
\hline Unemployed & 0.45 & 0.45 & 0.26 & 0.46 & 0.45 & 0.60 & 0.05 & 0.41 & 0.45 & -1.27 & 0.07 \\
\hline Life-Quality Index (0-100) & 62.17 & 62.12 & 0.12 & 63.19 & 61.89 & $2.74^{c}$ & 0.33 & 63.64 & 61.67 & $3.01^{c}$ & $2.59^{\mathrm{a}}$ \\
\hline Receives remittances & 0.09 & 0.08 & 0.31 & 0.08 & 0.08 & -0.30 & 0.01 & 0.12 & 0.08 & $2.12^{b}$ & 0.04 \\
\hline Urban & 0.91 & 0.90 & 0.71 & 0.93 & 0.90 & $2.70^{c}$ & -0.04 & 0.92 & 0.89 & 1.55 & -0.05 \\
\hline Lives in Santo Domingo & 0.35 & 0.35 & 0.41 & 0.36 & 0.34 & 0.79 & -0.04 & 0.46 & 0.33 & $4.60^{c}$ & 0.02 \\
\hline Observations & 1080 & 2050 & & 600 & 2530 & & & 303 & 2227 & & \\
\hline
\end{tabular}

Note: This shows baseline means for the control group (1); the treatment group (2); attritors in the follow-up group (3); non-attritors (4); non-attritors with incomplete information in key variables (6); and non-attritors with complete information (7). T tests and significance levels for mean difference between columns 1 and 2,3 and 4 , and 6 and 7 are shown. To test for whether attrition or complete information on key variables differs across treatment and control groups, columns 5 and 8 , respectively, show the difference-in-difference (DD) estimate: $\left[T_{-}(x=1)-T_{-}(x=0)\right]-\left[C_{-}(x=1)-C_{-}(x=0)\right]$, where $T$ and $C$ stand for treated and control individuals, and $x$ for attrition or complete information

a Significant at $10 \%$, ${ }^{\text {s }}$ significant at $5 \%$, ${ }^{c}$ significant at $1 \%$ 
Table 6 Balance of the sample of young women

\begin{tabular}{|c|c|c|c|c|c|c|c|c|c|c|c|}
\hline & \multicolumn{3}{|c|}{ Original randomization } & \multicolumn{4}{|c|}{ Attrited } & \multicolumn{4}{|c|}{ Complete information } \\
\hline & Control & Treatment & $t$ & Yes & No & $t$ & DD & No & Yes & $t$ & DD \\
\hline Age & 18.38 & 18.44 & -1.03 & 18.35 & 18.44 & -1.26 & 0.01 & 18.55 & 18.42 & 1.49 & -0.17 \\
\hline Rosenberg's self-esteem score & 23.59 & 23.82 & -0.81 & 24.13 & 23.64 & 1.43 & 0.60 & 23.4 & 23.66 & -0.42 & -0.73 \\
\hline Married & 0.28 & 0.18 & $3.10^{c}$ & 0.22 & 0.22 & 0.15 & -0.02 & 0.23 & 0.22 & 0.18 & 0.12 \\
\hline Number of children & 0.38 & 0.29 & $2.09^{b}$ & 0.31 & 0.33 & -0.30 & 0.06 & 0.33 & 0.33 & -0.05 & 0.09 \\
\hline Mother & 0.33 & 0.27 & $1.87^{\mathrm{a}}$ & 0.27 & 0.30 & -0.80 & 0.11 & 0.29 & 0.30 & -0.19 & 0.10 \\
\hline Attend school & 0.41 & 0.39 & 0.55 & 0.39 & 0.40 & -0.32 & -0.14 & 0.49 & 0.39 & $1.73^{\mathrm{a}}$ & -0.13 \\
\hline Incomplete primary educ. & 0.15 & 0.16 & -0.18 & 0.20 & 0.14 & $1.78^{\mathrm{a}}$ & 0.02 & 0.10 & 0.15 & -1.17 & 0.06 \\
\hline Complete primary educ. & 0.05 & 0.03 & 1.16 & 0.04 & 0.04 & 0.10 & 0.03 & 0.04 & 0.04 & -0.14 & 0.07 \\
\hline Incomplete secondary educ. & 0.55 & 0.63 & $-2.20^{b}$ & 0.52 & 0.62 & $-2.36^{b}$ & -0.08 & 0.69 & 0.62 & 1.25 & $-0.24^{b}$ \\
\hline Complete secondary educ. & 0.04 & 0.04 & 0.42 & 0.04 & 0.04 & 0.10 & -0.06 & 0.01 & 0.04 & -1.35 & -0.05 \\
\hline More than secondary educ. & 0.00 & 0.00 & 0.75 & 0.00 & 0.00 & -0.51 & 0.00 & 0.00 & 0.00 & -0.38 & 0.00 \\
\hline Missing education & 0.05 & 0.03 & 1.09 & 0.07 & 0.03 & $2.11^{\mathrm{b}}$ & 0.02 & 0.03 & 0.03 & -0.33 & 0.04 \\
\hline No data on education & 0.15 & 0.10 & $1.98^{\mathrm{b}}$ & 0.13 & 0.12 & 0.24 & 0.06 & 0.14 & 0.12 & 0.53 & 0.11 \\
\hline Number of jobs & 0.14 & 0.17 & -0.93 & 0.19 & 0.16 & 1.01 & $0.13^{\mathrm{a}}$ & 0.19 & 0.15 & 0.72 & $-0.19^{a}$ \\
\hline Employed & 0.02 & 0.02 & 0.12 & 0.02 & 0.01 & 0.57 & -0.04 & 0.00 & 0.02 & -1.06 & -0.01 \\
\hline Salaried worker & 0.01 & 0.01 & 0.25 & 0.00 & 0.01 & -1.13 & 0.00 & 0.00 & 0.01 & -0.84 & 0.00 \\
\hline Unemployed & 0.44 & 0.45 & -0.15 & 0.46 & 0.44 & 0.27 & 0.11 & 0.39 & 0.45 & -0.92 & -0.01 \\
\hline Life-Quality Index (0-100) & 63.87 & 64.08 & -0.31 & 64.72 & 63.83 & 1.08 & 1.21 & 64.43 & 63.75 & 0.61 & 2.24 \\
\hline Receives remittances & 0.07 & 0.11 & $-1.92^{\mathrm{a}}$ & 0.08 & 0.10 & -0.53 & 0.02 & 0.13 & 0.09 & 0.87 & -0.06 \\
\hline Urban & 0.93 & 0.91 & 0.82 & 0.94 & 0.91 & 1.18 & 0.03 & 0.98 & 0.90 & $2.14^{\mathrm{b}}$ & -0.06 \\
\hline Lives in Santo Domingo & 0.38 & 0.39 & -0.42 & 0.40 & 0.39 & 0.29 & -0.05 & 0.53 & 0.37 & $2.76^{c}$ & -0.10 \\
\hline Observations & 291 & 519 & & 166 & 644 & & & 80 & 564 & & \\
\hline
\end{tabular}

Notes: This table shows baseline means for those in the control group (column 1); in the treatment group (column 2); attritors in the follow-up (column 3); non-attritors (column 4); non-attritors but with incomplete information in key variables (column 6); and non-attritors with complete information (column 7). $T$ tests and significance levels for the mean difference between columns 1 and 2,3 and 4, and 6 and 7 are also shown. To test for whether either attrition or having complete information on key variables differs across treatment and control groups, columns 5 and 8 , respectively, show the difference-in-difference (DD) estimate: $\left[T_{(x=1)}-T_{(x=0)}\right]-\left[C_{(x=1)}-C_{(x=0)}\right]$, where $T$ and $C$ stand for treated and control individuals, and $x$ either for attrition or having complete information

${ }^{a}$ Significant at $10 \%$, ${ }^{b}$ significant at $5 \%$, ${ }^{\text {significant at } 1 \%}$ 
Table 7 Overall JE effects on pregnancy (probit, marginal effects)

\begin{tabular}{llll}
\hline Pregnancy & $(1)$ & $(2)$ & (3) \\
& All women & Age 16-19 & Age 20-29 \\
\hline Treatment & -0.026 & $-0.078^{\mathrm{a}}$ & -0.009 \\
& $(0.021)$ & $(0.041)$ & $(0.024)$ \\
Mean dep. var. for control group & 0.35 & 0.389 & 0.337 \\
Observations & 2,227 & 564 & 1,663
\end{tabular}

Notes: Robust standard errors clustered at the course level in parentheses. All models include a dummy variable for whether the follow-up interview was in 2011 and a variable for individual's age

a Significant at $10 \%$

Table 8 Correlation matrix of residuals

\begin{tabular}{llllll}
\hline & Pregnancy & $\begin{array}{l}\text { Total CPS } \\
\text { score }\end{array}$ & $\begin{array}{l}\text { Rosenberg } \\
\text { scale }\end{array}$ & $\begin{array}{l}\text { Total Grit } \\
\text { scale }\end{array}$ & $\begin{array}{l}\text { Expectations } \\
\text { index }\end{array}$ \\
\hline Pregnancy & 1 & - & - & - & - \\
Total CPS score & -0.079 & 1 & - & - & - \\
Rosenberg scale & -0.091 & 0.289 & 1 & - & - \\
Total Grit scale & -0.066 & 0.563 & 0.370 & 1 & - \\
Expectations index & -0.048 & 0.238 & 0.127 & 0.211 & 1 \\
\hline
\end{tabular}

Table 9 Overall JE effects on fatherhood: newborns

\begin{tabular}{llll}
\hline Is newborn's father the JE beneficiary? & $(1)$ & $(2)$ & $(3)$ \\
& All men & Age 16-19 & Age 20-29 \\
\hline Treatment & -0.005 & 0.006 & -0.009 \\
& $(0.019)$ & $(0.027)$ & $(0.025)$ \\
Mean dep. var. for control group & 0.110 & 0.0679 & 0.132 \\
Observations & 1329 & 440 & 889
\end{tabular}

Note: Robust standard errors clustered at the course level in parentheses

Table 10 Overall JE effects on fatherhood: number of newborns

\begin{tabular}{llll}
\hline Number of new children of male JE beneficiary & $(1)$ & $(2)$ & $(3)$ \\
& All & Age & \multicolumn{1}{l}{ Age } \\
& men & $16-19$ & $20-29$ \\
\hline Treatment & 0.008 & 0.028 & -0.001 \\
& $(0.024)$ & $(0.037)$ & $(0.031)$ \\
Mean dep. var. for control group & 0.123 & 0.0741 & 0.149 \\
Observations & 1329 & 440 & 889 \\
\hline
\end{tabular}

Note: Robust standard errors clustered at the course level in parentheses 


\section{Appendix 2}

\section{About the Construction of the Expectations Index}

The follow-up survey included a module of 13 questions that asked about individual, subjective expectations in 5 years' time from the survey. The questions are "how likely do you think is that when you are [current age +5 ] you...: (1) had finished an education level higher than the one you currently have; (2) live in a better neighborhood and have the house and car that you want; (3) live in the Dominican Republic; (4) have your own business; (5) have the job that you want; (6) have achieved your professional aspirations or goals; (7) have achieved your aspirations or goals for personal or family life; (8) keep your current group of friends; (9) have a problem with a relative (parents, siblings, partners, ex-partners, children); (10) had committed a delinquent act or been in jail; (11) get infected with HIV/AIDS; (12) have someone closer to you who get infected with HIV/AIDS; and (13) have someone closer to you (family or friend) dead in a violent act. From this list, we selected the items (1), (2), (4), (5), (6), and (7), which are related to expectations about individual labor outcomes or wellbeing, to construct our expectations index.

For this, we use principal component factoring analysis. Applying the Kaiser criterion (i.e., retain those factors with eigenvalues equal or higher than 1 ), we keep only factor 1 , which explains the $49 \%$ of the total variance. Our expectation index corresponds to the predicted values of a regression scoring based on varimax rotated factors. Figure 1 shows its distribution for the whole sample, for the whole sample of women, and for adolescent females.

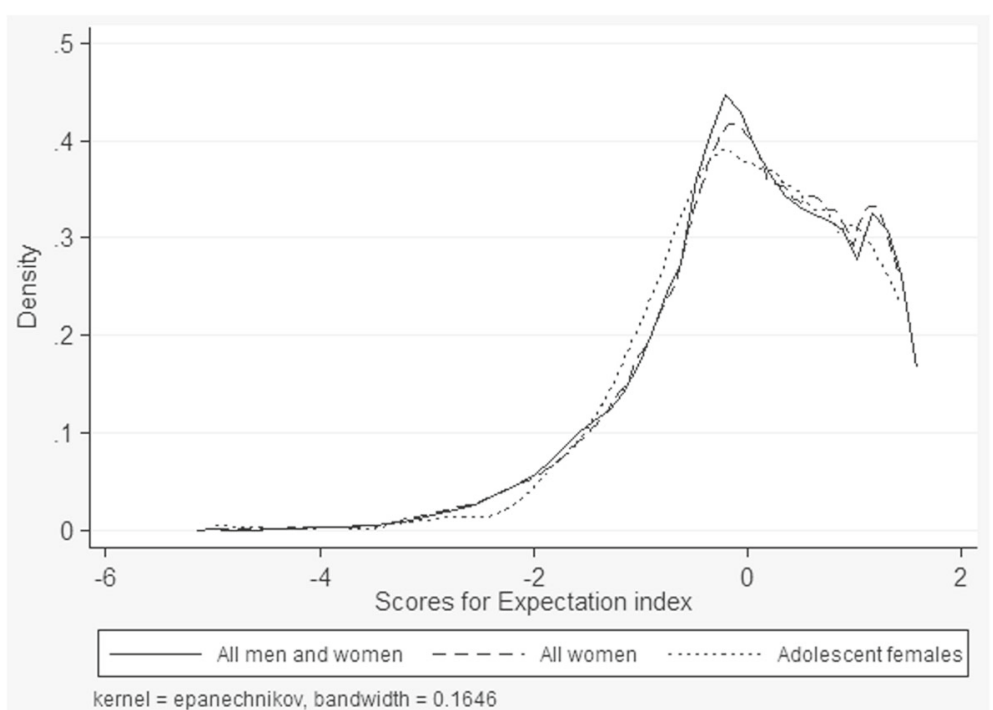

Fig. 1 Kernel density estimation of expectation index 


\section{Acknowledgements}

We are thankful for the collaboration of Brígida García, advisor on evaluation of the program, and to Paloma Acevedo, Rosangela Bando, Mariano Bosch, Oscar Mitnik, and Norbert Schady for their comments. We also gratefully acknowledge the comments received from Maria Laura Alzúa and Francisco Ferreira as well as other participants at the 2013 Network of Inequality and Poverty (NIP) meeting in Argentina, the Ninth IZA/World Bank Conference "Employment and Development" the nineteenth Latin American and Caribbean Economic Association (LACEA), the seventh annual meeting on the Economics of Risky Behaviors (AMERB), and internal seminars at the Inter-American Development Bank (IDB). The views expressed in this paper are those of the authors and should not be attributed to the IDB. We would also like to thank the anonymous referee and the editor for the useful remarks.

Responsible editor: David Lam

\section{Competing interests}

The IZA Journal of Labor \& Development is committed to the IZA Guiding Principles of Research Integrity. The authors declare that they have observed these principles.

\section{Author details}

${ }^{1}$ Inter-American Development Bank, 1300 New York Avenue, N.W., 20577, Washington, D.C., USA. ${ }^{2}$ Inter-American Development Bank, 1300 New York Avenue, N.W., 20577 Washington, D.C. , USA.

Received: 5 August 2016 Accepted: 27 October 2016

Published online: 08 December 2016

\section{References}

Acs G (1996) The impact of welfare on young mothers' subsequent childbearing decisions. J Hum Res 31(4):898-915

An CB, Havemanand R, Wolfe B (1993) Teen out-of-wedlock births and welfare receipt: The role of childhood events and economic circumstances. Rev Econ Stat 75:195-208

Arceo-Gomez E, Campos-Vazquez R (2014) Teenage pregnancy in Mexico: evolution and consequences. LA J Econ 51(1):109-146

Ashcraft A, Lang K (2006) The consequences of teenage childbearing. NBER Working Paper No. 12485, August. doi: 10.3386/w12485. http://www.nber.org/papers/w12485

Azevedo JP, Lopez-Calva LF, Perova E (2012). Is the baby to blame? An inquiry into the consequences of early childbearing. World Bank Policy Research Working Paper 6074, World Bank, Washington, DC, USA

Berthelon M, Kruger D (2014) The impact of adolescent motherhood on education in Chile. IZA Discussion Paper 8072 Institute for the Study of Labor, Bonn, Germany

Betcherman G, Dar A, Olivas K (2004) Impacts of active labour market programs: new evidence from evaluations with particular attention to developing and transition countries. Social Protection Discussion Paper 0402, World Bank, Washington, DC, USA

Brea M (2010) Interpretación de las escalas CPS, Rosenberg y GRIT y propuestas de revisión para mejorar la confiabilidad. Unpublished manuscript

Calero C, Rozo SV (2016) The effects of youth training on risk behavior: the role of non-cognitive skills. IZA J Labor \& Dev $5(1): 1-27$

Card D, Ibarrarán P, Regalia F (2011) The labor market impacts of youth training in the Dominican Republic. J Labor Econ 29(2):267-300

Carrasco H (2012) El Embarazo Adolescente en Hogares Pobres de la República Dominicana: Evidencia a partir de la EEPS 2010. Unpublished manuscript

Chevalier A, Viitanen TK (2003) The long-run labour market consequences of teenage motherhood in Britain. J Pop Econ 16(2):323-343

Cygan-Rehm K, Riphahn RT (2014) Teenage pregnancies and births in Germany: patterns and developments. CESifo Working Paper 4836. CESifo Group Munich, Munich, Germany

Duckworth AL, Peterson C, Matthews MD, Kelly DR (2007) Grit: Perseverance and passion for long-term goals. J Pers Soc Psychol 92(6):1087-1101

Duflo E, Glennerster R, Kremer M (2007) Using randomization in development economics research: a toolkit. Handb Dev Econ 4:3895-3962

Ermisch J, Pevalin DJ (2005) Early motherhood and later partnerships. J Pop Econ 18(3):469-489

Favara M, Lavado P, Sanchez A (2016) Understanding teenage fertility, cohabitation, and marriage: the case of Peru. IZA Discussion Paper. IZA Discussion Paper. Paper No. 10270 https://ssrn.com/abstract=2849755

Fazio MV (2011) Análisis de la percepción de los empleadores acerca de las pasantías y las perspectivas de inserción laboral en esas empresas. Technical Report 240. Inter-American Development Bank, Washington, DC, United States

Fletcher JM, Wolfe BL (2009) Education and labor market consequences of teenage childbearing evidence using the timing of pregnancy outcomes and community fixed effects. J Hum Res 44(2):303-325

Gonzalez Velosa C, Ripani L, Rosas D (2012) How can job opportunities for young people in Latin America be improved? Technical Report 345. Inter-American Development Bank, Washington, DC, United States

Goodman GK A, Walker I (2004) Understanding the effects of early motherhood in Britain: the effects on mothers. IZA Discussion Paper 1131. Institute for the Study of Labor, Bonn, Germany

Heckman J, Lalonde RJ, Smith J (1999) The economics and econometrics of active labor market programs. In: Ashenfelter O, Card D (eds). Handb Labor Econ. Elsevier, New York, United States

Heckman J, Stixrud J, Urzua S (2006) The effects of cognitive and noncognitive abilities on labor market outcomes and social behavior. J Labor Econ 24(3):411-482 
Hotz VJ, McElroy SW, Sanders S (1997) The impacts of teenage childbearing on the mothers and the consequences of those impacts for government. In: Maynard R (ed). Kids Having Kids. The Urban Institute Press, Washington, DC, United States

Ibarrarán P, Rosas D (2009) Evaluating the impact of job training programs in Latin America: evidence from IDB funded operations. J Dev Effect 2(1):195-216

Ibarrarán P, Ripani L, Taboada V (2014) Life skills, employability and training for disadvantaged youth: evidence from a randomized evaluation design. IZA J Labor \& Dev 3(1):1-24

Ibarrarán P, Kluve JL, Ripani, Shady DR (2015) Experimental evidence on the long term impacts of a youth training program. IZA Discussion Paper 9136. Institute for the Study of Labor, Bonn, Germany

International Labour Organization (2015) Panorama Laboral 2014. América Latina Y el Caribe. International Labour Organization-Latin America and Caribbean Office, Lima, Peru

Kearney MS, Levine PB (2012) Explaining recent trends in the U.S. teen birth rate. Technical Report 17964. National Bureau of Economic Research, Cambridge, MA, United States doi:10.3386/w17964. http://www.nber.org/papers/w17964

Kearney MS, Levine, PB (2014) Media influences on social outcomes: the impact of MTV's 16 and pregnant on teen childbearing. NBER Working Paper Series 19795. National Bureau of Economic Research

Klepinger D, Lundberg S, Plotnick R (1999) How does adolescent childbearing affect the human capital and wages of young women? J Hum Res 34(3):421-448

Levine D, Painter G (2003) The schooling costs of teenage out-of-wedlock childbearing: analysis with a within-school propensity-score-matching estimator. Rev Econ Stat 85(4):884-900

Lundberg S, Plotnick R (1990) Effects of state welfare, abortion, and family planning policies on premarital childbearing among white adolescents. Fam Pla Persp 22(6):246-251

Lundberg, S, Plotnick R (1995) Adolescent premarital childbearing: do economic incentives matter? J Labor Econ 13(2):177-200

Näslund-Hadley E, Binstock G (2010) The miseducation of Latin American girls: poor schooling makes pregnancy a rational choice. Technical Report 204. Inter-American Development Bank, Washington, DC, United States

Plotnick R (1992) The effects of attitudes on teenage premarital pregnancy and its resolution. Am Soc Rev 57(6):800-811

Plotnick, R (1993) The effect of social policies on teenage pregnancy and childbearing families in society. Cont J Hum Serv 74(6):324-328

Plotnick, R (2007) Adolescent expectations and desires about marriage and parenthood. J Adol 30:943-63

Rascon-Ramirez E (2014) Teenage pregnancy and motherhood in England: do parent's educational expectations matter? $\mathrm{PhD}$ thesis. Institute for Social and Economic Research, University of Essex

Rosenzweig MR, Wolpin KI (1995) Sisters, siblings, and mothers: the effect of teen-age childbearing on birth outcomes in a dynamic family context. Econometrica 63(2):303-326

Wolfe B, Wilson K, Haveman R (2001) The role of economic incentives in teenage nonmarital childbearing choices. J Pub Econ 81:473-511

World Bank (2012) Teenage pregnancy and opportunities in Latin America and the Caribbean. On teenage fertility decisions, poverty and economic achievement. World Bank, Washington, DC, United States

World Bank (2014) World development indicators. World Bank, Washington, DC, United States

\section{Submit your manuscript to a SpringerOpen ${ }^{\circ}$ journal and benefit from:}

- Convenient online submission

Rigorous peer review

- Immediate publication on acceptance

- Open access: articles freely available online

- High visibility within the field

- Retaining the copyright to your article

Submit your next manuscript at $\boldsymbol{\triangleright}$ springeropen.com 